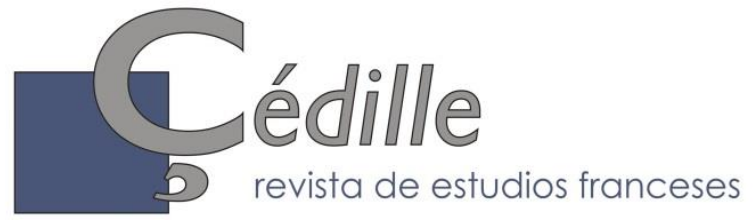

ISSN: $1699-4949$

no 20 (otoño de 2021)

Varia

\title{
Una creadora olvidada: Irène Hillel-Erlanger, entre el simbolismo y las vanguardias
}

\author{
Isabel GoNZÁLEZ GIL \\ Universidad Complutense de Madrid \\ migonzalezgil@ucm.es* \\ https://orcid.org/o00o-0002-4349-0957
}

\section{Resumen}

Este artículo trata sobre una autora desconocida de la vanguardia francesa, Irène Hillel-Erlanger, y su obra principal, Voyages en kaléidoscope, una insólita novela poética, publicada en 1919, perteneciente al género de lo «maravilloso-científico», la protociencia-ficción desarrollada en Francia entre 1900 y 1930. Fruto de la hibridación de los lenguajes del simbolismo y del experimentalismo vanguardista, en la novela se aprecian las tensiones entre estas dos direcciones, que estudiaremos a partir del análisis de aspectos temáticos y formales, como son el alegorismo, el hermetismo, el fragmentarismo o la visualidad, así como la pluralidad textual y discursiva. Para terminar, abordaremos la poética de la mirada subyacente al invento utópico del caleidoscopio, en el contexto del final de la I Guerra Mundial.

Palabras clave: escritoras vanguardistas, canon, lo maravilloso-científico, protociencia-ficción, alquimia.

\section{Résumé}

Cet article porte sur une auteure méconnue de l'avant-garde française, Irène Hillel-Erlanger, et sur son œuvre principale, les Voyages en kaléidoscope, un insolite roman poétique, publié en 1919, appartenant au genre du " merveilleuxscientifique », la protoscience-fiction développée en France entre 1900 et 1930. Fruit de l'hybridation des langages du symbolisme et de l'expérimentation avantgardiste, dans le roman s'aperçoivent des tensions entre ces deux directions, qui seront étudiées à travers l'analyse d'aspects thématiques et formels, tels que l'allégorisme, l'hermétisme, le fragmentarisme ou la visualité, ainsi que la pluralité textuelle et discursive. Pour finir, nous aborderons la poétique du regard sous-jacente à l'invention utopique du kaléidoscope, dans le contexte de la fin de la Première Guerre mondiale.

Mots clé: écrivaines avant-gardistes, canon, le merveilleux-scientifique, protoscience-fiction, alchimie.

\section{Abstract \\ This article is about an unknown author of the French avant-garde, Irène Hillel-Erlanger, and her main work, Voyages en kaléidoscope, an unusual poetic}

*Artículo recibido el 2/01/2021, aceptado el 23/09/2021. 
novel, published in 1919, belonging to the genre of the "Scientific-marvellous", the proto-science-fiction developed in France between 1900 and 1930. As a result of the hybridisation of the languages of symbolism and avant-garde experimentalism, the novel shows the tensions between these two movements, which will be studied through the analysis of thematic and formal aspects, such as allegory, hermeticism, fragmentarism, or visuality, as well as textual and discursive plurality. Finally, we will address the poetics of the gaze underlying the utopian invention of the kaleidoscope, in the context of the end of the First World War.

Keywords: avant-garde writers, canon, the scientific-marvellous, proto-science fiction, alchemy.

\section{Introducción}

Todo lo que rodea la figura y la obra de Irène Hillel-Erlanger (18781920) tiene un aura quimérica, fabulosa e improbable: su breve pero fulgurante aparición como escritora en un ambiente, como el de la vanguardia parisina, bajo un férreo control masculino (Bonnet, 2012); su colaboración pionera con la cineasta Germaine Dulac en la labor de guionista y en la fundación conjunta de la productora D.H.; su muerte unos meses después de la publicación de su principal obra, Voyages en kaléidoscope; la leyenda surgida en torno a su desaparición, atribuida al desvelamiento de secretos alquímicos; y, por último, lo extraño de su omisión casi completa del canon, a pesar de haber escrito una de las obras más interesantes de la literatura de vanguardia.

Pese a la buena acogida del libro, que contó con la reseña de Louis Aragon en el $\mathrm{n}^{0} 9$ de Littérature, y de la que se hicieron eco publicaciones como Paris-midi, Le Temps, L'Humanité o Le Figaro, los Voyages cayeron muy pronto en el olvido, al que sin duda contribuyó la repentina muerte de su autora apenas cinco meses después de su publicación, debida a una rápida enfermedad de garganta. Hasta la aparición de la edición y el estudio crítico de Jacques Simonelli en 1996, la conservación del recuerdo de esta innovadora e insólita novela poética se debió fundamentalmente a los alquimistas Fulcanelli y Eugène Canseliet ${ }^{1}$.

Las primeras obras de la autora iban firmadas con el pseudónimo de Claude Lorray. Bajo este nombre literario publicó, en sus comienzos, Poésies, suivies de diverses adaptations de Shakesperare, Marlowe, Keats, Shelley (1909), La chasse au Bonheur (1912), así como el resto de su producción poética anterior a 1912. No será hasta 1916, año en el que funda con Germaine Dulac la productora D.H., cuando comience a firmar como Irène Hillel, en la redacción del guion de Sours ennemis.

${ }^{1}$ Fulcanelli - seudónimo del célebre y enigmático autor de libros de alquimia, cuya identidad se desconoce- mencionaba la obra en Les demeures philosophales (1929). Su discípulo Eugène Canseliet le dedica un extenso comentario en su libro Deus logis alchimiques en marge de la science et de la histoire (1945). 
Descendiente de una antigua y acaudalada familia judía, Hillel-Erlanger hizo gala de una gran libertad de espíritu y apertura intelectual. En su salón recibía a escritores y artistas como Czeslaw Milosz, Anna de Noailles, Valéry Larbaud o Kees Van Dongen. Su hijo Philippe Erlanger recordaba así el ambiente cultural que la rodeaba y los lazos que creó: "Amie de Saint-John Perse, elle scandalisait davantage encore en accueillant les dadaïstes. Elle ne s'intéressait pas moins à la politique et aux hommes qui changeaient les mosaïques de la planète» (Simonelli, 1996: 150). Su obituario en Paris-midi destacaba de ella que «vivait plus inténsement encore qu'elle n'écrivait» (Échos, 1920: 2), así como su labor de mecenas de jóvenes escritores y artistas.

\section{Entre el simbolismo y las vanguardias}

El periodo en el que Irène Hillel-Erlanger desarrolló su producción literaria (1909-1919) se tiende entre dos mundos ${ }^{2}$. El simbolismo daba sus últimos estertores y todavía no había emergido la nueva conciencia que desencadenó en Europa la I Guerra Mundial. Roberto Bolaño, en su novela corta Amuleto, imaginaba, en un ejercicio ucrónico, un imposible encuentro entre modernismo y vanguardia al que denominaba «la isla inexistente», que hubiera supuesto una nueva estética y que hubiera sido transformador. Como si de una hija de este improbable cruce se tratara, Hillel-Erlanger alea en su obra el ludismo gráfico y formal de las experimentaciones vanguardistas con la aspiración hermética que inspiraba las creaciones simbolistas de un Villiers de l'Isle-Adam o del magiste Péladan³.

El estilo de Voyages en kaléidoscope es veloz, urbano, fragmentario. Se suceden distintos narradores y tipologías textuales (artículos de prensa, hojas de diario, cartas). La segmentación, las variaciones gráficas y las repeticiones la acercan a la forma poética y en algunas de sus páginas a la poesía visual. Christophe Wall-Romana (2007: en línea) ha señalado a propósito del poema «Par amour», dedicado a la actriz americana Pearl White, aparecido en 1919 en Littérature, que se trata de la primera artista en haber desarrollado una cinegrafía de la página, por su trabajo paralelo en la visualidad literaria y la escritura de la imagen en los guiones. Esta importancia de lo visual se muestra en los Voyages, además de en la relevancia de la disposición gráfica, en la inclusión del dibujo de un termómetro diseñado por Kees

\footnotetext{
2 Sobre esta frontera de la I Guerra Mundial, como división infranqueable entre dos épocas, hablaba Pierre Brunel (1997: 3) en su libro Apollinaire entre deux mondes. Reflexionaba también Bauman a propósito de ello en su libro The Art of Life, a propósito del cambio generacional que supuso la contienda, aspecto que desarrollaremos en el quinto apartado. 3 Acerca del fragmentarismo y el experimentalismo gráfico, conviene señalar que, si bien estas características estaban ya presentes en simbolistas como Mallarmé (Un coup de dés), considerado el iniciador de la revolución del lenguaje poético (Kristeva, 1974) que eclosionará en el siglo XX, no se convertirán en dominantes hasta el periodo de vanguardias.
} 
van Dongen, que acompaña el primero de los viajes del caleidoscopio («termómetros humanos»), y una portada atravesada por símbolos geométricos, que dialogan con el texto.

La visualidad, lo múltiple, el hibridismo, el juego, el dinamismo, así como la ironía y el humor, son rasgos de esa modernidad que se entrecruza con el aparato simbólico del texto, al que mueve como una fuerza centrífuga, y con un lenguaje que todavía revela la influencia de la estética simbolista, tanto en su forma interior - alegorismo, caracteres arquetípicos, síntesis de opuestos, temática hermética- , como exterior - preferencia por las mayúsculas del lenguaje esotérico- .

Si bien se considera al simbolismo generalmente agotado en la frontera de la I Guerra Mundial, pueden apreciarse en la obra rasgos de ese movimiento que tuvo la facultad «d'excéder son propre présent» (Illouz, 2014: s.p.). Esta pervivencia se manifiesta así, en primer lugar, en el imaginario del que se sirve la autora para la construcción alegórica de los personajes y de los espacios que moran y transitan. El idílico y lujoso oasis en el que reside Grâce (una mansión iniciática llena de aves exóticas, piedras preciosas, rosales, palmeras) remite a las atmósferas legendarias del simbolismo más preciosista. Se encuentra aquí situado en el centro de una ciudad en pleno movimiento, con la que contrasta y de la que aísla. Del mismo modo, la mansión de Véra entronca también con una imaginería previa, decadente y de refinada perversión:

Dans la fumée parfumée de cigarettes ambrées à bouts de rose ; quels papillotants papotages. Que de perles. Quels tissus de mille-et-une nuits. Autour des spécialités de Haut-Luxe : / Pyramides de fruits forcés. Pâtes confites aux points d'épingles. Sorbets au cyanure (Hillel-Erlanger, 1996: 47).

En segundo lugar, hay que destacar el alegorismo explícito de la obra. Tanto los espacios como los personajes invitan a una lectura en clave, cuyo sentido espiritual es explícito en el caso de estos segundos. Como señalaron autores como Henri Mazel (1894) o Camille Mauclair (1897), la alegoría fue uno de los rasgos que caracterizó frecuentemente las creaciones simbolistas, concebidas como obras de doble sentido, en las que los elementos textuales encarnan un ideal o pensamiento del autor. Voyages en kaléidoscope invita al menos a dos lecturas, una primera literal y una segunda espiritual, arquetípica, que proporciona las claves de la iniciación alquímica. La obra se convierte, así, en cifra de la Obra (Opus magnum), de un itinerario místico que los lectores pueden desentrañar para alcanzar, como el personaje principal, Joël Joze, la metanoia, la transformación interior. Probablemente sea este el aspecto más inequívocamente simbolista que alienta la obra, la concepción redentora del arte y de la imaginación, propia de la espiritualidad heterodoxa finisecular, erigida como una forma de transgresión y ruptura de 
los convencionalismos de la sociedad materialista, burguesa (Parisse, 2000).

Sin embargo, si bien los simbolistas eran almas «éprises de jadis», tomando la expresión de Remy de Gourmont (1892: 5) en Le latin mystique, la fuerza de atracción de los Voyages se dirige en dos direcciones contrarias: hacia la tradición depositaria de la sabiduría, que propone un itinerario salvífico, un absoluto atemporal encarnado en los valores de pureza y aristocracia espiritual, y hacia el nuevo sueño democrático que representa el cinematógrafo, así como los discursos de los nuevos medios y figuras que emergen en la urbe moderna, que subvierten y ponen en cuestión dichos valores, como se desarrollará en el capítulo cuarto. El propio invento del caleidoscopio de Joël Joze es una metáfora perfecta de este cruce, al representar la modernidad de lo atávico, donde lo innovador se encuentra con la sabiduría pretérita, en esa síntesis química que constituyó un ideal espiritual y literario para el simbolismo.

\section{Lo maravilloso-científico}

Al igual que se trata de una obra liminar en lo formal y lo temático, también lo es en su atribución genérica. Ya hemos mencionado cómo la prosa se segmenta hasta aparecer visualmente como verso. Además, por su argumento, podríamos considerarla un exponente de la proto-ciencia ficción 4 , pues la obra especula con la invención de un aparato científico utópico. Más concretamente, le conviene el término de le merveilleux-scientifique, popularizado por Durand de Gros en 1894, y, posteriormente, impulsado por Maurice Renard, en su manifiesto publicado en Le Spectateur en 1909: «Du roman merveilleux-scientifique et de son action sur l'intelligence du progrès». Fleur Hopkins (2019: en línea), en su texto sobre el ciclo organizado sobre el tema por la $\mathrm{BnF}$, titulado Le merveilleux-scientifique. Une science-fiction à la française, señalaba acerca de este género literario, poco conocido en Francia y que se desarrolló entre 1900 y 1930, que «[...] n'a pas pour but d'imaginer l'avenir [...], ou d'enseigner des rudiments scientifiques sur fond d'aventures [...], mais plutôt de regarder le présent de manière légèrement décalée, afin de donner matière à penser à son lecteur».

Según Hopkins (2020), era habitual en este tipo de ficción científica el recurso a las ciencias ocultas y a tradiciones heterodoxas. Como explicaba Renard (2018: en línea) en su manifiesto, aquello que los humanos ignoramos y aquello de lo que dudamos es la materia de lo maravilloso científico:

Car la science est incapable de nous montrer nulle merveille, au sens propre du mot. Loin de là, elle est la grande tueuse de miracles. Il n'y a de merveille que dans le mystère, dans l'inexpliqué [...]. Mais, puisqu'il s'agit d'un merveilleux scientifique, comment pourrons-nous

4 Con este nombre, se suele denominar a las obras de ciencia ficción antes del nacimiento del género como tal en los años 20, y de su posterior estudio crítico. 
concilier ces exigences, d'aspect contradictoire, qui veulent que nous prenions nos sujets à la fois dans la science et dans ce qui n'est pas la science? - Nous agirons exactement comme fait le savant qui s'attaque aux problèmes de l'inconnu ; nous appliquerons à l'inconnu et au douteux les méthodes de l'investigation scientifique.

Se trata de obras, considera Renard, que portan siempre intenciones reformadoras, algo que puede apreciarse en el componente utópico del caleidoscopio, que persigue una transformación de las conciencias.

También resulta especialmente descriptiva la categoría de «ciencia ficción hermética» introducida por Roberto Lépori (2014: 25) para designar un conjunto de obras inspiradas en las ciencias ocultas y en corrientes heterodoxas, «compuesta por filosofía, religión, teología, misticismo, alquimia, cábala, magia práctica, visiones, mesianismos, revelaciones, espiritismo, estados alterados de conciencia, paranoia, etc.», aunque su corpus es fundamentalmente latinoamericano, el término permanece perfectamente aplicable a este texto.

\section{Una novela alquímica en la modernidad}

Voyages en kaléidoscope trata sobre la invención, por parte del científico Joël Joze, de un aparato óptico utópico: un nuevo caleidoscopio, mucho más ambicioso que el conocido juego de espejos inventado por David Brewster, y cuya finalidad es la de transformar la visión del mundo de los espectadores a través de un proceso de intercambio metafórico. Como el Edison de L'Ève future, Joël Joze es un adepto de las artes ocultas, decepcionado con la enseñanza oficial. Responde al estereotipo del genio atormentado: nervioso, sombrío y expresivo, provocando en su entorno tantas adhesiones entusiastas como burlas incrédulas. Los Voyages comienzan con el fracaso estrepitoso de su estreno ante la alta sociedad parisina, narran la posterior recuperación del inventor y la historia del triunfo multitudinario del caleidoscopio, del que se transcriben cinco sesiones, para concluir con la caída final del personaje y la destrucción del aparato.

Exteriormente parecido a unos prismáticos metálicos sobre una base de acero, el caleidoscopio es un artefacto que permite a la vez registrar y proyectar las imágenes en una pantalla, de manera similar a la experiencia del cinematógrafo que los hermanos Lumière habían patentado dos décadas antes. Pero a diferencia de las sesiones de cine, en las caleidoscópicas se persigue producir una transformación imaginal (Caeiro, 2010) del público asistente, para restituir una visión no egoísta en la sociedad5.

5 Conviene diferenciar la finalidad de lo que comúnmente se entiende por alquimia, el arte de transmutar los metales en oro, de la alquimia espiritual. Como explicaba Evelyn Underhill (2006: 164-166) en su obra Mysticism, publicada en 1911, de los distintos imaginarios místicos estudiados por ella «ninguno es tan completo, tan pintoresco, y tan poco entendido en la actualidad, como el de los "filósofos herméticos" o alquimistas espirituales». El 
La premisa de la que parte este novum 6 concebido por Joze es que el universo, tal y como los ojos lo perciben, difiere totalmente de su forma verdadera. Los seres humanos solo pueden ver aquello que está en ellos mismos. Para superar este idealismo radical y obtener una visión intersubjetiva, se busca realizar un intercambio de visiones. El procedimiento, como se explica en el texto, consiste en captar en las pupilas de cada ser vivo las imágenes de todas las cosas visibles, condensarlas, fijarlas y comprimirlas según métodos descubiertos por Joze, para obtener de este modo una síntesis química, que permitiría ver estas imágenes proyectadas en la pantalla como metáforas animadas:

Transformées dans l'appareil même, au moyen de très mystérieux fluides, de sels et de métaux précieux, les Visions se concentrent instantanément sous forme de pastilles platinées qui peuvent ensuite servir à un nombre illimité d'expériences. Ainsi, chacun de nous, selon ses tendances, découvrira le SENS CACHÉ de toutes choses. Et ce sens caché, relatif, nous sera restitué dans son sens absolu, par comparaison avec une autre manière de voir. En somme, fusion de l'individu et de la collectivité dans une sorte de physico-chimie trascendental et humoristique : L'HARMONIE NAISSANT D'ÉCHANGE DE VUES ! (Hillel-Erlanger, 1996 [1919]: 17).

Al modo de una sesión de cine-terapia o cine-meditación, el caleidoscopio pretende lograr, a través de un hervidero de imágenes insólitas que cuestionan la vida cotidiana, un cambio de mirada. "Spécieuse outrecuidance, utopie subversive, d'où ne pouvait sortir que la confusion d'un illuminé, privé de sens commun» (Hillel-Erlanger, 1996 [1919]: 18), dirá el narrador periodista en el tono burlón que recorre toda la noticia.

Irène Hillel-Erlanger se inspiró de las teorías de Stanislas de Guaïta y de su libro Au seuil du mystère, citado en los Voyages, para los principios ocultistas del caleidoscopio. En la obra se mencionan los maestros ocultistas (cuyos principales nombres en la modernidad en Francia fueron Eliphas Lévi, Péladan, Guaïta o Papus), la Biblia y la Cábala, concretamente la teoría de las correspondencias, la atracción y la luz astral como las bases del aparato7. Esta última se refiere específicamente a la concepción ocultista de la imagen y la visión espirituales. Según explicaba Evelyn Underhill (2006

oro alquímico representa la humanidad divina, la «condición áurea del hombre, su principio perfecto».

${ }^{6}$ Fernando Ángel Moreno (2009: 68) define este término, introducido por Darko Suvin, como «un adelanto humanístico que aparece en el argumento de una obra literaria».

7 Más que el término de hermetismo, a este conjunto sincrético de corrientes espirituales le conviene la denominación de Antoine Faivre de «hermésisme» (que se corresponde con el inglés «hermeticism» frente a «hermetism»), una tendencia esotérica que cobra fuerza a partir del Renacimiento, y que unía hermetismo y alquimia, junto con la astrología, la magia y la cábala hebrea (Riffard, 2008: 144). 
[1911]: 174), la luz astral es uno de los axiomas principales de la magia. Se trata de un agente universal extrasensorial que une e interpenetra el mundo material. El plano astral, de manera similar a lo que la Sociedad Teosófica denominaba los anales akhásicos, contiene todas las imágenes pasadas y futuras y es considerada por ello el fundamento de la clarividencia y la adivinación.

La posibilidad de captar las imágenes de forma extraordinaria fue también el objetivo de la optografía, corriente paracientífica popular en el siglo XIX que buscaba obtener en las retinas de los cadáveres las imágenes que vieron antes de morir. Estos métodos ocultistas guardan una analogía con el propio proceso cinematográfico, pero a diferencia de este, el caleidoscopio no busca representar imágenes externas, sino las internas, la irreproducible y sinuosa visualidad de la conciencia. Como ha estudiado Fleur Hopkins (2019) en su artículo "Approche épistémocritique du merveilleuxscientifique», las ciencias y pseudo ciencias ópticas (como la oftalmología, la catóptrica y la óptica fisiológica), desempeñaron un papel fundamental en el género.

Tras el fracaso de la representación en la mansión de la condesa Véra, y antes de conseguir que el caleidoscopio funcione, Joël Joze ha de recorrer una serie de etapas que se corresponden con las de un proceso iniciático. En los Voyages hay un alegorismo declarado, que invita a un juego hermenéutico desde la portada - en la que se utilizan símbolos geométricos para representar a los tres personajes principales que rodean a Joël Joze- y, especialmente, en el frontispicio, en el que se proporcionan claves de lo que estos deberían significar: Joze es la humanidad superior, «(si peu) alternativement Voyante et Aveugle», Grâce, lo que su nombre indica; Véra, la voluptuosidad («Parfaite Forme du Plaisir feroce») y el joven Gilly, «le sel de la Terre», el leal servidor (13-14).

El antagonismo entre Grâce y Véra, que encarnan en la obra dos estereotipos de la mujer tan recurrentes en el simbolismo como lo fueron la mujer beatífica y la «femme fatale», prefigura la división del alma de Joël Joze, que se debate entre su ambición y su anhelo espiritual, entre lo terrenal y lo celeste ( $c f$. González Gil, 2019). Véra es una bailarina millonaria idolatrada en Europa y en América, es poderosa, frívola, egoísta, mundana. Grâce, por el contrario, es reservada, sabia, altruista, y vive recluida, rodeada de pocos fieles. Grâce y Véra desempeñan, además, el par actancial de ayudante y oponente, que se verá sin embargo aparentemente subvertido en el capítulo final, pues, siguiendo el principio hermético de la coincidentia oppositorum, Grâce y Véra - hermanas enfrentadas- son esencialmente la misma persona bajo dos aspectos, «double émanation de l'Inconnaissable» (Hillel-Erlanger, 1996 
[1919]: 14) y, se advierte al lector, si una aumenta es en detrimento de la otra $^{8}$.

En la primera sesión, en la residencia de Véra, Joze no consigue hacer funcionar el caleidoscopio ante la concurrencia: la pantalla queda en blanco, lo que provoca su debacle social y el rechazo de la bailarina. No puede entenderse este intento malogrado como un suceso extraordinario en la época. Por el contrario, los lectores estaban familiarizados con este tipo de experimentos ocultistas que se habían convertido en un fenómeno de moda en el cambio de siglo, así como los intentos reiterados de probarlos científicamente. El mediumnismo y las mesas parlantes eran un atractivo más de muchas reuniones sociales, y se sabe que suscitaron el interés de grandes escritores en distintos países europeos, como Víctor Hugo, Yeats o Valle-Inclán (González Gil, 2015b). Célebres fueron los experimentos fallidos realizados con la médium italiana Eusapia Palladino, o el propósito de Harry Houdini de desenmascarar los trucos ocultistas. Hay que tener en cuenta que en las últimas décadas del siglo XIX y las primeras del siglo XX, el esoterismo y el ocultismo estaban mucho más integrados y divulgados que en la actualidad entre los círculos artísticos y literarios europeos y el gran público. Joseph Grasset, en su libro L'occultisme hier et aujourd'hui, que se publicó inicialmente en la Revue des deux mondes, denominó «le merveilleux préscientifique» a todo ese conjunto de fenómenos ocultos de los que se esperaba que pudieran en un futuro ser probados por la ciencia: «Les faits occultes sont en marge ou dans le vestibule de la science, s'efforçant de conquérir le droit de figurer dans le texte du livre ou de franchir le seuil du palais» (Grasset, 1907: 9).

La alquimia fue uno de los saberes ocultos que experimentó un cierto renacer en el cambio de siglo (González Gil, 2015a). Strindberg publicaba en 1898 su novela Inferno, en la que relata su propio viaje a los abismos en París en la persecución del sueño alquímico. En 1896 se había fundado la Société Alchimique de France, y años después aparecerían la Società Alchemica Italiana (1909) y la Alchemical Society (1912). Durante ese periodo en Francia, vieron la luz los ocho volúmenes de textos de alquimia comentados, del químico e historiador francés Marcelin Berthelot (Monod-Herzen, 1978: 205).

En su estudio "A la lueur de l'Ourse», Simonelli (1996: 156-157) interpreta el esquema simbólico de la obra a partir de las dos columnas del árbol cabalístico (Chessed y Geburah, gracia y rigor) y del simbolismo del templo de Salomón: Jakin y Boaz, fuerza y sabiduría, lo masculino y lo femenino, sustancia y materia, el principio solar y mercurial, que corresponderían con los triángulos ascendentes y descendentes de la portada, y con las figuras de Grâce y Véra. Según la doctrina alquímica, no es posible alcanzar la realización espiritual, el ser humano trascendido, sin superar las

${ }^{8}$ El carácter alegórico de las figuras femeninas se ve reforzado por la carencia de apellido, Joël Joze es el único personaje en obtener dicho tratamiento singularizador en la obra. 
separaciones artificiales del entendimiento, y comprender la unión de los opuestos. El joven Gilly, el Ojo Derecho (sic) de Joze - porque ve más recto que los demás- , representa en la obra la mirada inocente necesaria para activar el proceso espiritual. Es gracias al encuentro con este joven repartidor de periódicos huérfano, en la brasserie de l'Espérance, como el inventor consigue finalmente poner en marcha el caleidoscopio. Gilly se convierte en su aprendiz, además de en narrador de los viajes, cuando Joze le propone que se compre una libreta para escribir sobre las proyecciones. Este encuentro con la persona clave para activar el caleidoscopio no hubiera sido posible sin la intervención de su benefactora y tercera figura alegórica central de su desarrollo, Madame Grâce. Será ella quien consiga rescatarlo de la deriva enloquecida en la que lo había sumido el fracaso del caleidoscopio y el rechazo de la condesa Véra.

El capítulo IV relata el encuentro de Joze con Grâce, una escena iniciática que condensa gran parte de la simbología alquímica de la obra. De ella se afirma que vive sola, en un círculo íntimo, ayudando a quien lo necesita. Sus gustos y conducta son opuestos a los de la mundana Véra. La descripción arquitectónica de la mansión de Grâce proporciona, como en los viejos grabados alquímicos (Roob, 1997), idea de las etapas a seguir por el neófito que busca la opus magnum: hace falta un permiso especial para entrar, por eso son tan pocos los que pueden visitarla; la entrada - el vestíbulo de Grâce- es un locus amoenus, un oasis en medio de París, con palmeras, limoneros, naranjos y ruiseñores; le sigue una escalera de cristal; y tres persianas, de sayo, tela de plata y largos hilos de oro - alusión a las tres fases alquímicas de la nigredo, albedo y rubedo, purificación, iluminación y unión- ; a través de ellas se accede a la sala del tesoro:

Rideau de Bure

certains, de haut parage, ont entr'ouvert

Rideau d'Argent

Rideau d'Or est très secret

et, dans la Salle du Trésor, seul ont pénétré des Simples.

A ceux-là, Grâce parle visage découvert

Devant les autres, quoi qu'ils implorent, toujours son

voile mystérieux (Hillel-Erlanger, 1996 [1919]: 42-43).

Como en todo proceso espiritual, el camino entraña un proceso ascético de simplificación, altamente restringido y de dificultad creciente. En esta sala del tesoro, se señala, solo han penetrado los simples, a los que Grâce les habla con el rostro descubierto. El símbolo del velo, y de la sabiduría velada, está ampliamente presente en la literatura ocultista9. Para acceder a esta revelación, se indica, los aspirantes debían pasar por un proceso de transformación personal que los permitiese entender y contemplar la realidad en su triple aspecto de Bien, Belleza y Verdad. Una vez que habían

9 Una de las obras más divulgadas de la literatura esotérica del siglo XIX se titulaba Isis Unveiled (1877), de la teósofa Madame Blavatsky. 
visto el rostro de Grâce, eran transportados a la Sala Sublime, en la que les instruía en los arcanos y les revelaba el nombre de su padre:

Quand les Simples ressortent de cet Entretien miraculeux ils sont tellement resplendissant qu'on a peine à les reconnaître. Leurs plus anciennes relations en demeurent stupides. Eux, désormais Intelligents, sentent que plus rien ne leur est impossible, parque rien plus ne leur est caché à cause de cette grande Lumière sur leurs Visages (Hillel-Erlanger, 1996 [1919]: 43).

Tras pasar Joze por este proceso, y beber del agua salutaire, Grâce le confiesa que le ha seguido en sus primeras exploraciones con el caleidoscopio, antes de que se extraviase con Véra. Grâce se convertirá desde ese momento en su protectora. Es gracias a su ayuda y al hallazgo de Gilly, como el caleidoscopio empieza a cosechar un enorme éxito de público, con 2000 salas programadas en toda Europa, 120 en París, con 3000 asientos en cada sala y un horario ininterrumpido desde las once de la mañana a la una de la madrugada.

El capítulo siete está dedicado a las transcripciones de algunas de estas sesiones caleidoscópicas, sorprendentes, hilarantes y grotescas. El primer viaje se llama los termómetros humanos («excursion humoristique enregistrée par M. Gilly») y está centrado en el espectáculo de las cosas cotidianas y en la caricatura social para desautomatizar la mirada estancada en las convenciones. La pantalla comienza proyectando múltiples tipos de saludos, más de veinte especies distintas (glacial, obsequioso, seco, caballeroso, amistoso, etc.), para entrenar la mirada de los espectadores a ver la vida como un espectáculo repleto de matices:

Si habitués au spectacle des Choses Quotidiennes que nous y prenons à peine garde. Ou bien, que nous sommes occupés exclusivement (et c'est dommage) à tirer de ce spectacle gratuit des conclusions d'intérêt privé - sans doute passionnates - mais chétives en portée psychique : il nous faut le secours stimulant et l'optique vivace de notre moderne Kaleido, pour obtenir du Salut, comme de toute Signe habituel, un rendement máximum, riche de sens absolu (Hillel-Erlanger, 1996 [1919]: 67).

Se burla, en esta sesión, de las etiquetas sociales. Los saludos son sustituidos por individuos portando, a modo de insignia, un termómetro que marca su temperatura social, como el diseño de Van Dongen que acompaña al texto, que muestra las siguientes marcas, por orden de temperatura descendente: «Sénégal», «chambres de malades», «bains-hauts», «vers à soie», «orangers», «zéro», «rivières gelées», «Paris 1879», «Bérésina» y "Alaska». Los individuos cuya temperatura se encuentra el extremo más cálido están enfermos, saturados de halagos, y en el extremo más frío se hallan 
aquellos lastimosos inadaptados que no han sabido adecuar sus termómetros al ideal grado cero, en torno al cual se localizan las regiones más fértiles y placenteras:

Sur chaque Individu nous observons un insigne. Détail d'habillement qui sert, sans supplement d'enquête, à établir le Droit-Social-aux-Révérences.

Cet insigne nécessaire n'est autre qu'un THERMOMÈTRE

Voyez : nous portons chacun le nôtre !... [...]

Un Thermomètre-Standard préside à nos destinées saluantes

(Ciel où serions-nous sans lui ? Privés de Boussole et de Pôle ? Livrés sur l'Océan du Monde à tous les Ecueils d'un Accueil inconsidéré ? Jetés sur tous les Récifs des Égards, des Regards intempestifs ou escamotés ? )(Hillel-Erlanger, 1996 [1919] : 69).

En la segunda sesión se acera un poco más la crítica social, presentando en pantalla con todo lujo de detalles a glotones de ostras y aficionados a los caracoles que se deleitan en un gran banquete, para luego dar el paso a la repulsiva escena de comedores de telas de arañas:

- Huîtres ou escargots ? - Kaleido n'a pas à se prononcer : la plus imperceptible pointe d'ail ne demeure hors ligne qu'en évitant les confidences.

Mais voici que l'œil magistral de notre Appareil-Ami vient saisir sur le vif un autre spectacle gastronomique. Plutôt sur le mort-vif ! Quels pauvres hères attablés devant une pitance de famine ? Quels Chevaliers de Sombre-Accueil ? Qu'est-ce qu'ils avalent? Pas possible ? Des Toiles d'Araignées !

(La Direction rappelle qu'un luxe de détails suggestifs est amplement fourni à l'écran. Séance ininterrompue jour et soir).

(Hillel-Erlanger, 1996 [1919]: 73-74).

El narrador proporciona la clave a continuación de las imágenes en pantalla: los glotones de ostras son seres un tanto obtusos, sin iniciativa, que se limitan a seguir sus rutinas hedonistas y a vivir según las normas ancestrales; los aficionados a los caracoles son los fantasiosos, seres disparatados por los que el narrador declara su preferencia; por último, los comedores de telas de araña representan ricos Midas, presos de comidas nauseabundas por falta de gusto, y siervos de lo que pensarán los demás.

El tercer viaje («alphabet») continúa con la crítica social, centrándose en la obsesión por la riqueza. Pone en escena caracteres de imprenta que, gracias a la magia caleidoscópica, cobran vida, en analogía con los seres 
humanos. Se reprocha la identificación del dinero con el único bien, y se destacan las múltiples formas que puede adoptar la miseria, ya sea la falta de salud, de alegría, de seguridad, de alma o, incluso, de la propia falta: «Misère peut être manque de:/ Santé/ Gaîté/ Sécurité/ Beauté/ Manque de Prestige/ Manque de Ressort/ Manque d'Air et d'Âme/ Manque d'Amour/ même, manque de Manque (grande misère)» (Hillel-Erlanger, 1996 [1919]: 76),

ainsi Public, quand ce Z-là «bizarre» te semblera plus difficile à vivre que tel $\mathrm{O},-$ amène, rond, plein de grâce dans son cercle égoïste, - (assis au beau milieu de «Joie» - pensé, peut-être à Kaleido : Nos Caractères (dit-il) son notre même Structure et la Substance de notre état.

(Hillel-Erlanger, 1996 [1919]: 77).

La cuarta sesión («Pieuvre») lleva a los espectadores hasta el banco Crédit International. Este viaje es uno de los más ingeniosos y críticos de toda la serie. Se muestra un recorrido histriónico por las oficinas, repleta de importantes señores preocupados y esclavizados por el dinero ( «GrandVassaux-de-la-Matière»). El capital aparece figurado como la EmperatrizPulpo, que estrecha a todos los seres humanos en sus tentáculos, a través de las necesidades de comida, bebida, vestimenta, calor, luz, etc., que capturan el cuerpo, el corazón y el espíritu, y de cuya sujeción es difícil liberarse, más que a través de engaños o de buenos propósitos para exculpar a la conciencia. Este es probablemente el viaje más crítico de todo el libro, en el que puede apreciarse un reproche de las ambiciones del grupo social y familiar de la autora, como descendiente que era de A. S. Camondo, poderoso banquero turco.

qui nous dira pourquoi

nous sommes TOUS asservis sur terre

à Elle

la Pieuvre-Impératrice?

(Un jour - prochain - Argent prendra un autre nom.

Oui. Kaleido voit très distinctement ces Grands-Vassaux-de-la-Matière, réduits à changer de Pavillon (couvrant leur marchandise). Ou même : bannis, pulverisés

Mais Pieuvre est toujours pareille. Satrape-Capital cède le pas : C'est un autre tyran, qui passe. Et voilà tout) (Hillel-Erlanger, 1996 [1919]: 79).

El último viaje («alibi») sirve una analogía con la instalación de un teléfono estropeado, en el que cada detalle toma forma humana. Trata sobre las esperas y desesperaciones ante la administración que decide el destino 
de la pila que no funciona. ¿Quién o qué probará su coartada cuando se comete una falta?, se pregunta el narrador. Este viaje, interrumpido por una falta de corriente, es el más breve y críptico por sus fallos técnicos finales, que acaban en varias líneas de puntos suspensivos. En la mención al cuidado de las cuerdas vocales, a los rigores de las leyes de la acústica y a una pila que no funciona, en su inacabamiento, puede leerse también - más allá de su sentido general dentro de la serie de desautomatización de situaciones corrientes- la preocupación de la autora por la enfermedad que terminará siendo fatal meses después de la publicación de la obra. "Après prouesses oratoires (dans ce Milieu éminemment sensible au charme de la Parole) / Pile / condamnée. Au rebut ! / Sera pilée !» (82).

Con una lógica propia de las asociaciones de ideas de la escritura automática, estos cinco viajes proponen un hervidero de escenas extravagantes y humorísticas que se suceden con un ritmo veloz. La segmentación de las frases en la secuencia reproduce en cierta forma la velocidad de las imágenes cinematográficas, aunque les diferencia, por un lado, el onirismo del caleidoscopio (pues las imágenes que se muestran son procesos interiores de la conciencia), así como el afán de penetrar en el sentido oculto de la vida cotidiana mediante el recurso a la caricatura y la deformación metafórica, para producir una renovación de la manera de mirar la vida de los asistentes.

Pero los Voyages no terminan con el éxito de las proyecciones. En el momento de triunfo del caleidoscopio, la antagonista Véra vuelve a hacerse presente en la vida de Joel Jöze. Incapaz de resistirse a las tentaciones de la bailarina, el inventor emprende su camino hacia la ruina, en el que engaña a Grâce y a Gilly.

Se revela también lo sucedido en el fracaso de la primera proyección. La explicación que ofrece Joze del suceso es que, mientras que la pantalla del caleidoscopio quedaba en blanco, él tuvo una extravagante visión "pesadillesca» de orugas y larvas, ataviadas elegantemente, producida por la decadente concurrencia. En el tiempo transcurrido desde el fiasco, señala, ha comprendido que se produjo porque la mirada cansada, aburrida y escéptica de los nobles asistentes era incapaz de verlo. Un público selecto, educado, nunca producirá fluídicamente más que una aglomeración sosa y átona, concluye. Hacía falta un ojo de niño para activar el descubrimiento.

La ambición de Joze y el deseo que siente por Véra le harán arriesgarlo todo para volver a su lado. Pese a los reproches de Grâce, que le acusa de duplicidad y de convertir el caleidoscopio en el instrumento de su vanidad, Joel acepta la invitación de la condesa para una nueva proyección en su residencia, roba el aparato, junto con algunas pastillas de proyección, y se marcha en el Rolls-Royce de Véra. En el siguiente capítulo, en el que se muestran las dramáticas consecuencias de la elección de Joze, el relato da un salto de dos años en el cuaderno de Gilly. Ha decidido escribir la biografía de su maestro y para ello ha de recordar lo sucedido dos años atrás, ya que 
él fue el único testigo. A través de imágenes y diálogos vivaces, narra su intento, junto con Grâce, de recuperar el caleidoscopio, en una aventura que se saldó con el desvelamiento de esta de su rostro, coronado por un diamante en su frente que ciega las miradas, y del parentesco que une a ambas $^{10}$.

\author{
Patron? \\ méconnaissable \\ blanc tremblant \\ Colère de la Comtesse \\ Colère de Mme Grâce [...] \\ Comtesse Véra toute révulsée \\ comme convulse \\ elle crie \\ - «Ma sœur!» \\ - « Oui moi Véra ! » moi l'Invisible - jadis vous le di- \\ siez par jeu - mais vous ne rirez plus de ma longue pa- \\ tience [...] (Hillel-Erlanger, 1996 [1919]: 105-106).
}

Grâce destruye el caleidoscopio, arrojándolo al suelo, lo que produce torrentes de electricidad que derrumbará las casas a su alrededor y prenderá fuego al barrio, provocando miles de víctimas carbonizadas o asfixiadas, «enfants - femmes - hommes - Héros - qui donnèrent leur Vie pour les autres» (108), y edificios en ruinas. Los personajes principales sobreviven, aunque algunos pagarán las consecuencias, Gilly con la rotura de un brazo y Joze acabará paralizado, temporalmente ciego y paralizado (tardará un mes en recuperar la vista y el uso de sus piernas). Una vez el caleidoscopio ha sido destruido, Gilly recobra su primer empleo, como vendedor de periódicos, y planea dedicarse a la redacción. Joze con la intención de mantenerse alejado de Véra y Grâce apoyándole en la distancia, mientras recobra dificultosamente la salud.

Si bien el argumento propone un recorrido simbólico perfectamente descifrable desde el esoterismo finisecular, los puntos de vista escogidos para la narración y el discurso de algunos personajes introducen notas de disenso en lo que de otro modo podría haber sido un discurso monológico. De entrada, la elección inicial de un reportero en el capítulo I para presentar al lector los acontecimientos permite ofrecer una visión desmitificadora de Joël Joze, al que en el paratexto inmediatamente anterior se había presentado como la Humanidad superior. Además, el título «Mystificateur ou dément», el tono irónico de la pieza, las afirmaciones del periodista de que Joze parte «de ce principe ultra-contestable et qui fera hausser nombre d'épaules pondérées» (16), «ne pouvait sortir que la confusion d'un illlu-

${ }^{10}$ Esta velocidad en la sucesión de imágenes es construida formalmente a través de la pronunciada segmentación del texto, el recurso constante a la elipsis y la reducción del discurso a los mínimos elementos. 
miné, privé de sens commun» (18), o la denominación de «pseudo-inventeur» (20), como ejemplos de notas críticas, proporcionan una mirada no complaciente, de un narrador que cuestiona el ocultismo y no es un admirador del personaje. Por otro lado, la imagen de Véra aportada por el reportero es muy distinta a la que revelarán sus cartas y la de los personajes, es la idealizada visión de sus contemporáneos sobre la condesa: «quand cette Inspiratrice annonça qu'elle produirait chez elle, pour la première fois, le Kaléidoscope et son auteur, quel courant de curiosité sympathique circula parmi l'élite de la société» (19). Además, las últimas frases de la noticia, «On ne sait pas encore ce qu'il est devenu, ni ce qu'on doit penser de cette manifestation insolite» (20), se posicionan en una incertidumbre muy diferente de las certezas y los absolutos del conocimiento iniciático.

Pero, sin duda, son las cartas el elemento que contribuye más a minar el discurso unívoco. Una parte importante de la historia está contada a través del intercambio epistolar. Joze, pese a ser el personaje central de la historia, nunca es el narrador. Su voz solo aparece directamente a través de sus cartas, como una más en la correspondencia con Véra y Grâce. El comportamiento manipulador de Joze, que las cartas manifiestan, la diferencia entre sus palabras y sus acciones, la ambición, el doble juego y la debilidad que revela, todo ello introduce grietas y tensiones en lo que pudiera haber sido un discurso monológico, y que se abre así a diferentes interpretaciones y a que el lector extraiga sus propias conclusiones. También, la elección de Gilly como el narrador de los últimos capítulos, pues su mirada inocente, pese a la idealización que experimenta con respecto a su maestro y a su apoyo hasta el final, deja sentir también las dudas con respecto a lo sucedido, tras la destrucción del caleidoscopio, cuando cuestiona a Joze y Grâce, y su afirmación de que «todo es necesario» (108). Frente a esto, se pregunta por la necesidad de lo ocurrido, por qué ha pasado y si todo tenía algún sentido:

Mme Grâce

Vous?

Pourquoi cela?

Le faillait-il ?

«Tout est nécessaire » dites-vous aussi ! Sans doute?

Je ne peux pas comprendre

alors je vois comme je peux

C'est tout. C'est peu

Je ne jugerai point.

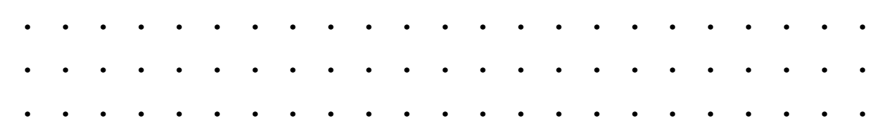

(Hillel-Erlanger, 1996 [1919]: 108).

Así, las indicaciones que la autora implícita ofrece en los paratextos sobre el significado alegórico de la obra y sus esquemas simbólicos - cuyo 
código es el hermético- quedan matizadas o problematizadas por otras visiones sociales propias de la modernidad urbana, y de los afectos, que también se introducen en la obra y que tienen la palabra.

Por último, el fragmentarismo de la trama, con sus cambios constantes de narrador y tipología textual, sus elipsis y saltos temporales que la acercan a la narrativa audiovisual, contribuye a proporcionar una visión puramente caleidoscópica (en ambos sentidos), humorística, fruto de diferentes perspectivas y voces y que permite más de una lectura. La unicidad del relato alquímico se ve cuestionado por la pluralidad de la(s) mirada(s) sobre él, lo que hace de esta obra "quimérica», cruce de géneros y de estilos, entre la prosa y la poesía, lo maravilloso y lo científico, la tradición y la ruptura, la seriedad y el humor, una novela que refleja perfectamente la transición y el cambio de lenguajes poéticos que tuvo lugar del simbolismo a la modernidad de las vanguardias.

\section{Una poética de la mirada al término de la I Guerra Mundial}

El periodo de la I Guerra Mundial y la posguerra introdujo importantes cambios tanto en la conciencia europea como en los códigos literarios que imperaban. Sentida como un antes y un después en el optimismo bélico que caracterizaba a una parte de los intelectuales y artistas (como captura lúcidamente Stefan Zweig en Die Welt von Gestern. Erinnerungen eines Europäers), dio lugar no solo a una transformación del mapa geopolítico sino a una auténtica conmoción cultural y estética. Explica Bauman (2009: 7778) que se produjo una brecha generacional, por el que «el "yo mismo" de antes de la Gran Guerra, el "yo mismo" de después y el "yo mismo" que abarcaba el "antes" y el "después" hablaban todos una lengua diferente. Los tres apenas podían comunicarse con los otros dos». Como ha estudiado Nicolás Beaupré (2006: 16), ya desde el principio de la I Guerra Mundial existió esta percepción de época separada:

Le premier conflit mondial fut d'abord perçu comme une « époque séparée » par les acteurs eux-mêmes, qui, dès les premiers mois de 1914, parlaient déjà de "Grande Guerre », ou de "Grande Époque », que ce soit pour l'exalter ou pour la déplorer avec ironie ou amertume.

La necesidad de superación de aquello que había podido conducir a la contienda fue una de las consecuencias. La búsqueda de la armonía, de la conciliación de opuestos, de una visión totalizante frente a una egoísta y estrecha, etc., pueden leerse como síntomas de esa necesidad de transformación colectiva que se hizo patente en los últimos años de la Gran Guerra y en la postguerra ${ }^{11}$. El componente utópico del caleidoscopio reside en el

${ }^{11}$ En este periodo aparecen otras obras que desarrollan una poética de la visión similar a los Voyages. En 1917, publica Valle-Inclán su novela experimental La media noche. Visión estelar de un momento de guerra, que comparte varias características con la obra de Hillel- 
ideal de un cambio de una visión individualista por una intersubjetiva, que rompiera con las convenciones y los automatismos y que devolviera una mirada nueva de la existencia humana. Shklovski hablaba en 1917 en «El arte como artificio» de la capacidad desautomatizadora de la literatura, frente a la concepción simbolista del pensamiento por imágenes. Este extrañamiento del hábito cuya divulgación imaginaba Hillel-Erlanger a gran escala y de la cual nos proporciona atisbos en los insólitos viajes tenía como fin declarado conseguir la armonía que surge del intercambio de visiones. La capacidad perturbadora del caleidoscopio era uno de los principios que Renard atribuía a la ciencia en su teoría sobre lo maravilloso científico (Hopkins, 2019). Frente a este ideal perseguido, el fracaso de Joze, debido a su propia debilidad, puede entenderse como signo de la desconfianza con respecto a las ambiciones de la humanidad que el inventor explícitamente representa.

La tópica de la decadencia, tan característica del fin de siglo, está presente en el libro en forma de crítica a la debilidad y el escepticismo de la clase alta y de los círculos artísticos, sumidos en la molicie y el aburrimiento de la abundancia, y su mirada gastada frente a la mirada nueva que introduce el joven plumilla, y que es susceptible de lograr la perseguida transformación social. Esta tópica se aúna con el fulgor de las perspectivas de cambio auspiciadas por los nuevos medios de masas, especialmente el cine, tan caro a la autora, y su capacidad para proporcionar otras visiones del mundo a un público amplio. Pues la transformación que perseguía el caleidoscopio no se limitaba, como en el peregrinaje místico o alquimia, a ser un camino solitario, sino que el caleidoscopio es un invento espiritual destinado a las multitudes, el sueño de una época nueva que democratizara el ideal alquímico, y que en el periodo posterior a la guerra cobra un nuevo sentido y alcance.

\section{Conclusiones}

Decía Joanna Russ (2018: 221) que «hay por todo el canon señales que dejan traslucir entierros prematuros». El de Irène Hillel-Erlanger ha sido sin duda uno de estos casos, y todavía hoy permanece oculta pese al interés que presentan sus Voyages en kaléidoscope, y que se abre en múltiples direcciones: como novela pionera de proto-ciencia ficción y uno de los más bellos exponentes del género de «lo maravilloso científico»; del periodo de transición y del cambio de lenguajes del simbolismo a las vanguardias, tal y como se ha estudiado en este artículo, así como de la literatura de vanguardia escrita por mujeres, cuyo papel a menudo ha sido obliterado y reducido a la función de musas y compañeras de los artistas.

Erlanger, como son la mezcla de rasgos simbolistas (temática esotérica, a la que subyace todavía una cosmovisión que aspira a absolutos sin fisuras) y vanguardistas, y sobre todo la búsqueda de una visión total, intersubjetiva, superadora de los códigos espaciales y temporales de la existencia individual (cf. González Gil, 2015b). 
En este artículo nos hemos centrado en su obra principal, Voyages en kaléidoscope, concretamente en uno de los aspectos críticos más evidentes e interesantes de la misma: cómo el texto muestra a la perfección las tensiones resultantes del hibridismo de lenguajes del simbolismo y el experimentalismo vanguardista, en el contexto del periodo de transición que rodea a la I Guerra Mundial, en el que se constata la necesidad de un profundo cambio, representado en la obra por la renovación de la mirada que el invento del caleidoscopio promete. Hemos abordado en el texto cómo la pluralidad textual y discursiva (especialmente la polifonía de instancias narrativas) problematiza lo que podría haber sido un discurso hermético monológico, proporcionado por el alegorismo explícito de los paratextos y por los esquemas simbólicos que vertebran la obra.

La importancia de desenterrar la memoria de las escritoras olvidadas, sostiene Russ (2018: 173), va más allá de la restitución de la pérdida que supone una omisión individual, convirtiéndose en un ejercicio fundamental para las futuras escritoras, como eslabón de la tradición literaria, ya que «cuando se entierra la memoria de nuestras predecesoras, se asume que no había ninguna y cada generación de mujeres cree enfrentarse a la carga de hacerlo todo por primera vez». Con este artículo se pretende dar uno de los primeros pasos para restablecer su lugar en el canon a esta autora, de la que todavía quedan numerosos textos por estudiar, especialmente su obra poética y audiovisual, y situarla en el mapa de una crítica para la cual, tanto en su país de origen como (aún más) en España, Irène Hillel-Erlanger sigue siendo, un siglo después de su muerte, acaecida en 1920, una completa desconocida.

\section{REFERENCIAS BIBLIOGRÁFICAS}

BAUMAN, Zygmunt (2009): El arte de la vida: De la vida como obra de arte. Barcelona, Paidós.

BEAUPRÉ, Nicolas (2006): Écrire en guerre, écrire la guerre. France, Allemagne, 1914-1920. París, CNRS Éditions.

BolAÑo, Roberto (1999): Amuleto. Barcelona, Anagrama.

BONNET, Marie-Josèphe (2012): «L'avant-garde, un concept masculin». Itinéraires. URL: http://journals.openedition.org/itineraires/1336

BRUNEL, Pierre (1997): Mythocritique, 2. Apollinaire entre deux mondes : le contrepoint mythique dans Alcools. París, Presses Universitaires de France.

CAEIRO RodrígueZ, Martín (2010): «Exponer lo imaginal: reproducir y representar». Arte, individuo y sociedad, 22: 1, 35-48.

CANSELIET, Eugène (1998 [1945]): Deux logis alchimiques en marge de la science et de l'histoire. París, J. C. Bailly.

«Échos»: Paris-midi: seul journal quotidien paraissant à midi, 24/o3/1920, 2. 
FULCANELLI (1973 [1929]): Les demeures philosophales et le symbolisme hermétique dans ses rapports avec l'art sacre et l'ésotérisme du grandœuvre. París, Jean-Jacques Pauvert.

GONZÁLEZ GIL, Isabel (2015a): «El imaginario alquímico en el modernismo», in Natalia Álvarez Méndez y Ana Abello Verano [eds.], Espejismos de la realidad: percepciones de lo insólito en la literatura española (siglos XIX$X X I$ ). León, Servicio de Publicaciones de la Universidad de León, 117-127.

GONZÁlEZ GIL, Isabel (2015b): Estética y poética de la contemplación en ValleInclán: La lámpara maravillosa. Tesis doctoral dirigida por Ángel García Galiano. Madrid, Universidad Complutense de Madrid. URL: https://eprints.ucm.es/id/eprint/ 29969

GONZÁLEZ GIL, Isabel (2019): «Un "fauno anacoreta”. Erotismo y ascetismo en las representaciones del poeta modernista", in $\mathrm{M}^{\mathrm{a}}$ del Rocío Oviedo, Jesús Cano y Cristina Bravo [eds.], Un universo de universos y una fuente de canciones. Madrid, Verbum, 141-155.

GOURMONT, Rémy de (1892): Le latin mystique, les poètes de l'antiphonaire et la symbolique au moyen âge. París, Éditions du Mercure de France. URL: http://gallica.bnf.fr/ ark:/12148/bpt6k55759246

GuAÏTA, Stanislas de (1890): Essais de Sciences Maudites I: Au Seuil du Mystère. París, Georges Carré Éditeur.

HILLEL-ERLANGER, Irène (1996 [1919]): Voyages en kaléidoscope. París, Éditions Allia.

HOPKINS, Fleur (2019a): «Le merveilleux-scientifique: une Atlantide littéraire». Cycle Merveilleux-scientifique. Le blog Gallica. URL: https://gallica.bnf.fr/blog/30042019/le-merveilleux-scientifique-une-atlantide-litteraire?mode $=$ desktop

Hopkins, Fleur (2019b): «Approche épistémocritique du merveilleux-scientifique». Romantisme, 183, 66-78.

Hopkins, Fleur (2020): «Un miroir déformé du temps présent: optogrammes et rétrovision dans l'imaginaire merveilleux-scientifique français». Revue d'histoire culturelle. URL: http://revues.mshparisnord.fr/rhc/index.php?id $=413$

ILLOUZ, Jean-Nicolas (2014 [2004]): Le symbolisme. París, Le livre de poche [formato Kindle].

LÉPORI, Roberto (2014): Mil años de ciencia ficción hermética latinoamericana [1492-250o] en tres episodios: Borges, la conspiración; Sor Juana y Antônio Vieira, íntimos herejes; Bizarros profetas ciberculturales. Tesis de maestría. São José do Rio Preto, Universidade Estadual Paulista "Júlio de Mesquita Filho”. URL: https://repositorio.unesp.br/bitstream/handle/11449/122239/ooo813391.pdf?sequence $=1$

MAUCLAIR, Camille (1897): «Souvenir sur le mouvement symboliste en France (1884-1897)». París, La Nouvelle Revue, 15 de octubre, 670-693.

MAZEL, Henri (1894): «Qu'est-ce que le Symbolisme ?». Revue de l'Ermitage, junio [apud Jean-Nicolas Illouz, Le symbolisme. París, Le livre de poche, 2014]. 
MONOD-HERZEN, Gabriel (1978): L'alchimie et son code symbolique. Mónaco, Éditions du Rocher.

MORENO, Fernando Ángel (2009): «La ficción prospectiva: propuesta para una delimitación del género de la ciencia ficción», in Teresa López Pellisa y Fernando Ángel Moreno Serrano (eds.), Ensayos sobre ciencia ficción y literatura fantástica: actas del Primer Congreso Internacional de literatura fantástica y ciencia ficción. Madrid, Asociación Cultural Xatafi, 65-93.

PARISSE, Lydie (2000): «Ésotérisme, modèle mystique et littérature à la fin du XIX ${ }^{\mathrm{e}}$ siècle», in Marie Blaise y Alain Vaillant (dir.), Crises de vers. Montpellier, Presses universitaires de la Méditerranée. URL: https://doi.org/10.4000/books.pulm.131

RENARD, Maurice (2018): «Du roman merveilleux-scientifique et de son action sur l'intelligence du progrès». Res Futurae. Revue d'Études sur la science-fiction. URL: https://journals.openedition.org/resf/1201

RIFFARD, Pierre A. (2008): Nouveau dictionnaire de l'ésotérisme. París, Payot.

Roob, Alexander (1997): Alchemy \& Mysticism: The Hermetic Museum. Colonia, Taschen.

RUSS, Joanna (2018 [1983]): Cómo acabar con la escritura de las mujeres. Traducción de Gloria Fortún. Sevilla y Madrid, Editorial Barret y Editorial Dos Bigotes.

SHKLOVSKI, Victor (2012 [1917]): «El arte como artificio», in Tzvetan Todorov (ed.), Teoría de la literatura de los formalistas rusos. Madrid, Siglo XXI, 77-98.

Simoneldi, Jacques (1996): "À la lueur de l'ourse», in Irène Hillel-Erlanger, Voyages en kaléidoscope. París, Éditions Allia.

UNDERHILL, Evelyn (2006 [1911]): La mística. Estudio de la naturaleza y desarrollo de la conciencia espiritual. Madrid, Trotta.

WALl-Romana, Christophe (2007): «Cinégraphie, ou la marge à derouler». Textimage. Revue d'étude du dialogue texte-image, 1. URL: https://www.revue-textimage.com/o1_en_marge/wall-romana1.htm

ZWEIG, Stephan (2001 [1941]): El mundo de ayer. Memorias de un europeo. Traducción de A. Orzeszek y Joan Fontcuberta. Barcelona, Acantilado. 